\title{
PRESENTING A SUITABLE QUICK CONSTRUCTION PATTERN USING PREFABRICATED COMPONENTS IN CRITICAL CONDITIONS
}

\author{
Mohammad Hosein RAZAVI ${ }^{1}$, Parviz ALIPOUR ${ }^{2, *}$ \\ ${ }^{1}$ Private Civil Engineering, Karaj Branch, Islamic Azad University, Karaj, Iran. \\ ${ }^{2}$ Civil Engineering Department, Islamic Azad University, Karaj, Iran. \\ corresponding author: alipour.parviz@gmail.com.
}

\section{Abstract}

Every year, many people in the world lose their homes due to natural disasters such as earthquakes, floods and so on. In critical situations, the use of prefabricated parts in the buildings has many technical and economic advantages. Hence, today, this technology is widely used in the industrialized societies. The purpose of this research is to provide an appropriate model for speeding up the process of constructing buildings using prefabricated parts in critical conditions. To do this, Analytic Network Process (ANP) approach has been used to select the best option for speeding up construction projects using prefabricated parts and in critical situations. In this study, the intended criteria are quality, time, cost, and strength. The options that we should compare and the best option among them, according to the criteria mentioned, are Lightweight Steel Frame (LSF) parts, steel parts and concrete parts. In order to find this prioritization, the viewpoints of civil engineers and construction experts have been used. It should also be noted that for the ANP method, the Super Decisions software has been used.
\end{abstract}

\section{Keywords:}

Fast building construction; Prefabricated parts; Critical conditions;

Earthquake;

ANP method.

\section{Introduction}

After a widespread natural disaster, residential areas are in some ways unusable, and survivors are inevitably temporarily resettled elsewhere [1]. In order to prepare for events such as earthquakes and floods that directly affect people's lives and settlement, it is necessary to evaluate the extent and the number of possible damages before a disaster happens [2]. In the process of prevention, reconstruction and rapid rescue operations, the disaster assessment is necessary since it helps planning and controlling the situation, which has a direct effect on crisis management [2]. Disasters such as earthquakes, floods and accidents are harmful events that many people face every year. These events and may cause various mental or physical health problems [2]. In recent years, heavy natural disasters happened several times. The severe impacts of these incidents have been highlighted in disaster areas [3]. Usually, after a natural disaster occurs on a large scale and in deep surfaces, residential areas will become somehow unusable [3]. For this reason, the first and most important issue that provides some kind of safety and relaxation for the affected people is having proper shelter and gathering the members of family [4]. A major fact about disasters is that at the time of occurrence, there cannot be much work in dealing with such disasters while their effects could be neutralized or minimized by predetermined planning. In this regard, many societies now consider postdisaster preparedness plans (from emergency to permanent housing) before the occurrence of such incidents [5].

Today, in developed countries in a critical situation, many construction projects are conducted using prefabricated and modular parts while in the Third World and developing countries, these new methods are used relatively less [5]. However, the awareness of engineers, specialists, and contractors in developing countries about modern construction technologies is increasing while still, the implementation of high-tech structures that can remain in post-crisis situations is of paramount 
importance [6]. When designing fast-constructed buildings, it seems that the use of prefabricated parts with desirable resistance is the most popular method. According to the studies, prefabricated parts have high quality while they are installed and highly resist against earthquakes [6]. Besides, prefabricated parts such as Lightweight Steel Frame (LSF) have appropriate strength and the process of installing them is conducted continuously. Thus, at the present time, they are used in the United Kingdom, America, Canada, Australia, Japan and some other developed countries [7]. This system is made of Cold-Formed Sections (CFS) and has been used extensively in the industrial production of office, commercial and residential buildings for about 20 years [7]. Lightweight Steel Frame (LSF) system is a good substitute for traditional manufacturing methods and found a special place in the construction industry of developed countries. The use of the LSF system, in addition to at least doubling the speed of construction process, leads to a $40 \%$ reduction in the consumption of steel.

\section{Research method}

In this research, through studying different works, different models were selected and, finally, the best one was presented. In this research, we use the Analytical Network Process (ANP) decisionmaking method and analyze the intended models, and compare the results with other models or the sample model. In general, the purpose of the (ANP) decision-making method is to structure the decision-making process according to a scenario influenced by multiple independent factors. This technique improves the (ANP) decision-making process as a multi-criteria decision-making tool by replacing the hierarchy with the network.

\subsection{Analytical network process}

The network analysis process is as the general Analytical Hierarchical Process (AHP) and its widespread form, thus, it has all its positive features, including the simplicity, flexibility of applying quantitative and qualitative criteria simultaneously, and the ability to assess compatibility in judgments. Moreover, it can communicate a follow-up (interdependencies and feedbacks) between and among decision elements, using a network structure rather than a hierarchical structure. The difference between a "hierarchical structure" and "network structure" is presented in Fig. 1. An Analytical Network Process (ANP) considers each issue and problem as a network of criteria, sub-criteria and options (all of which are called the elements) that have been gathered together in clusters. All elements in a network can communicate in any way. In other words, in a network it is possible the feedback and interconnection between and among clusters [8].

Therefore, the ANP consisted of two parts: control hierarchy and network communication. The control hierarchy links together the goal, metrics, and sub-criteria and influences the internal relationship of the system, and involves a network connection between elements and clusters. This ANP capability allows for the consideration of interdependencies between elements, and thus provides a precise view of the complexities of urbanization. The influence of elements on other elements in a network is considered by a super matrix [9].

(a)

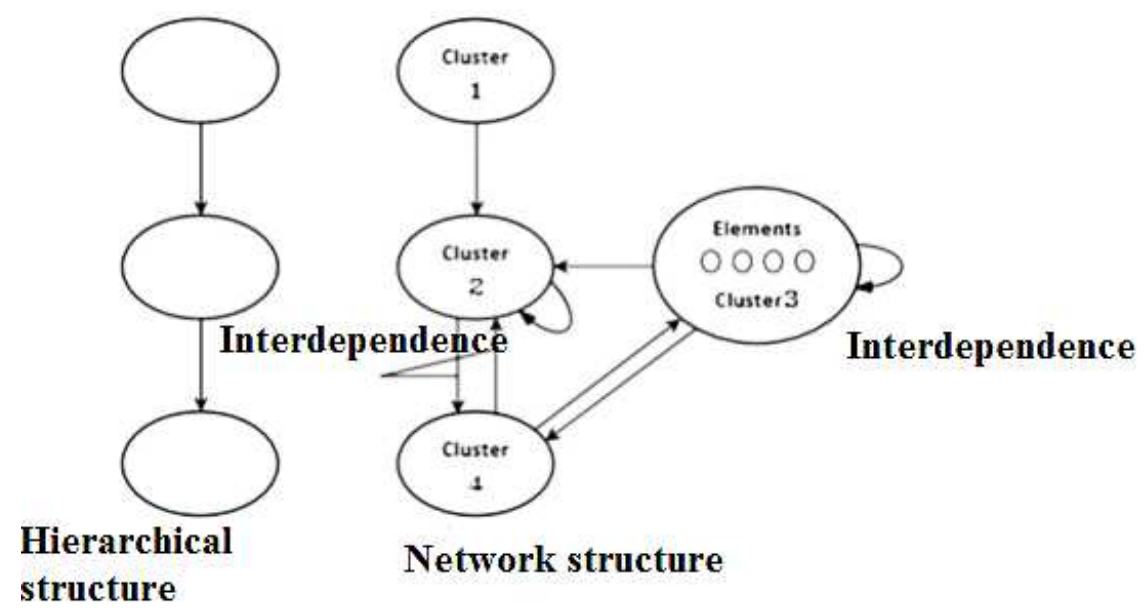

Fig. 1: Structural difference between a "hierarchical" and "network" [9]. 


\subsection{Introducing a model to transform the problem or topic into a network structure}

The subject of the problem must be obviously transformed into a logical system like a network. This network structure can be achieved through brainstorms or any other suitable method, such as the Delphi method or the nominal group method. At this step, the subject or problem is converted into a network structure in which the nodes are presented as clusters. Elements inside a cluster may be related to one or all of the other cluster elements (influenced on them or by them will be influenced), arrows indicate these relationships (outer dependence). Additionally, the elements inside a cluster may be have an interdependence between themselves (inner dependence), such relationships being denoted by an arc connected to that cluster (Fig. 1b).

\subsection{Formation of paired-comparison matrix and determination of priority vectors}

Similar to the pair comparisons performed in AHP, the decision elements in each cluster are compared based on their importance in relation to the two-by-two control criteria. The clusters themselves are also compared according to their role and their effect on achieving the goal. Decision makers need to make decisions about the paired comparison of the elements or clusters themselves. In addition, interdependencies between elements of a cluster should also be compared two by two. A special vector can represent the effect of each element on another element. The relative importance of the elements is measured based on the Saaty's 9-quantity scale (like AHP). In this section, the local priority vector is calculated which indicates the relative importance (importance coefficient) of the elements or clusters obtained by the following equation [10].

$A \times W=\lambda_{\max } W$,

$A$ - Paired comparison matrix of criteria,

$W$ - Special vector (coefficient of importance),

$\lambda_{\max }$ - The largest numerical special value.

To calculate the special vector $w$, Saaty Tomas has presented several methods. If the calculations are to be done without the use of specific software, the geometric mean approximation method is preferred. Therefore, at this stage, internal priority vectors are computed.

\subsection{Formation of the super matrix and its conversion to the limit super matrix}

In order to achieve the general priorities in a system, the interactions of the internal priority vectors (i.e., $W_{s}$ calculated) are entered in the appropriate columns of a matrix. As a result, a super matrix (actually a partitioned matrix) obtain, which each section of this matrix shows the relationship between two clusters in a system.

For example, a three-level structure of the objective, criteria, and options are presented in two forms hierarchical (a) and network (b) in Fig. 2. The super-matrix of the hierarchical state (a) can be as follows [10]:

(a)

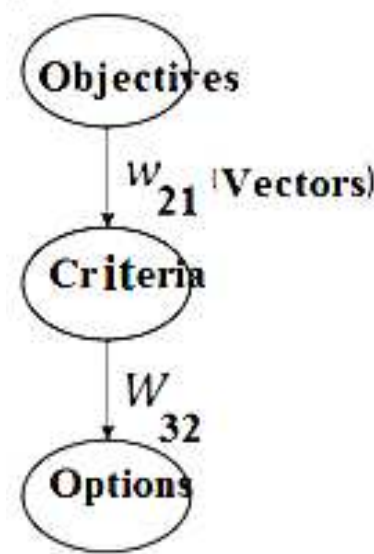

Fig. 2: Hierarchical structure (a) and network (b) [10]. (b)

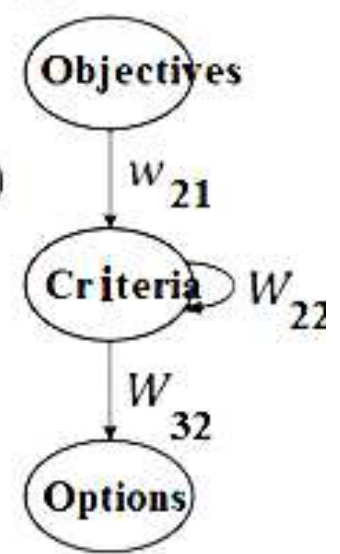




$$
\begin{aligned}
& \text { 总 }
\end{aligned}
$$

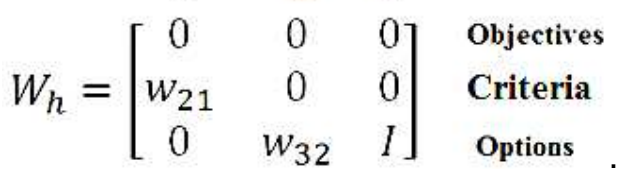

In this super matrix, $W_{21}$ and $W_{32}$ are the vectors that respectively indicate the target effects on criteria and the effects of criteria on options, and $I$ is the unit matrix. If the metrics have the mutual effects, the hierarchical process becomes a network process. (Fig. 2b) The interactions of the criteria on each other by entering $W_{22}$ in the $W_{h}$ super matrix are as follows.

$$
\begin{aligned}
& \text { ڤัٌ } \\
& W_{h}=\left[\begin{array}{ccc}
0 & 0 & 0 \\
W_{21} & W_{22} & 0 \\
0 & W_{32} & I
\end{array}\right] \begin{array}{l}
\begin{array}{l}
\text { Objectives } \\
\text { Criteria } \\
\text { Options }
\end{array} \\
\end{array}
\end{aligned}
$$

This kind of matrix is called the primitive super matrix. The unweighted super-matrix obtains by replacing the vector of internal priorities (importance coefficients), elements and clusters in the primitive super matrix.

In the next step, the weighted super-matrix is calculated by multiplying the unweighted supermatrix values in the cluster matrix. Then, by normalizing the weighted super matrix, the super matrix from the column view is converted to a random position.

In the third stage (and final), limit super matrix obtains is calculated via exponentiation all the elements of the weighted super-matrix until the divergence is being achieved (through repetition), or in other words, all the elements of the super matrix are the same [10].

$\lim W^{k}$

where $W$ is a weighted super-matrix.

\subsection{Choosing the best option}

If the super matrix is composed in the third step, the whole "network" is considered in which, that is, the options are also included in the super matrix, and the general priority of the options can be obtained from the column for the options in the normalized limit super matrix. If the super matrix is only the part of the network that has interdependent and the options are not considered in the super matrix, then the next calculation is required to obtain the overall priority of the options. The option with the most general priority is chosen as the best option for the topic [10].

\subsubsection{The methods of collecting and analyzing data}

In order to collect the data needed to prioritize the options, pairwise comparison questionnaires were prepared and sent to the experts. After integrating the judgments and analyzing the data, the criteria and project performance options are prioritized. The statistical population of this research is civil engineers and construction specialists. The sample size of this study was 30 people, which was obtained by simple random sampling method.

The analytic network process (ANP) method has been used to select the best option to construct building quickly using prefabricated construction materials and in critical situations. The criteria for this study are quality, time, cost and strength. According to the mentioned criteria, the best options are LSF, steel and concrete materials. In order to find the priority between these materials, 
opinions of 30 civil engineers and construction experts were used. It should also be noted that Super Decisions software has been used for the ANP method. In the ANP method, several steps should be taken to choose the best option. These steps include making the model, pairwise comparisons, forming a super matrix (including unweighted, weighted and limit super matrices) and choosing the best option.

\section{Data analysis}

The research method is that by defining the objectives, criteria and options, the criteria must be compared with each other with pairwise comparison method (PCM), and then the final option was determined based on the pairwise comparisons.

The problem should be expressed in a transparent way and then with a network should be broken down with a logical system. The above structure can be achieved using decision makers' mindset and through methods such as brainstorm or other appropriate methods. The first step in the ANP method is the structure drawing of the problem network. In order to form the network structure of the problem, criteria and research options must first be identified. Using research literature, library studies, and experts' opinions, the effective criteria in the quick construction process of the building was screened and categorized using pre-fabricated parts in critical situations. After identifying and categorizing the research criteria, the research options were identified. In this study, the research choices of the best type of prefabricated components for the building fast construction should be selected among the LSF options, steel and concrete parts. The model for this research is presented in Fig. 3.

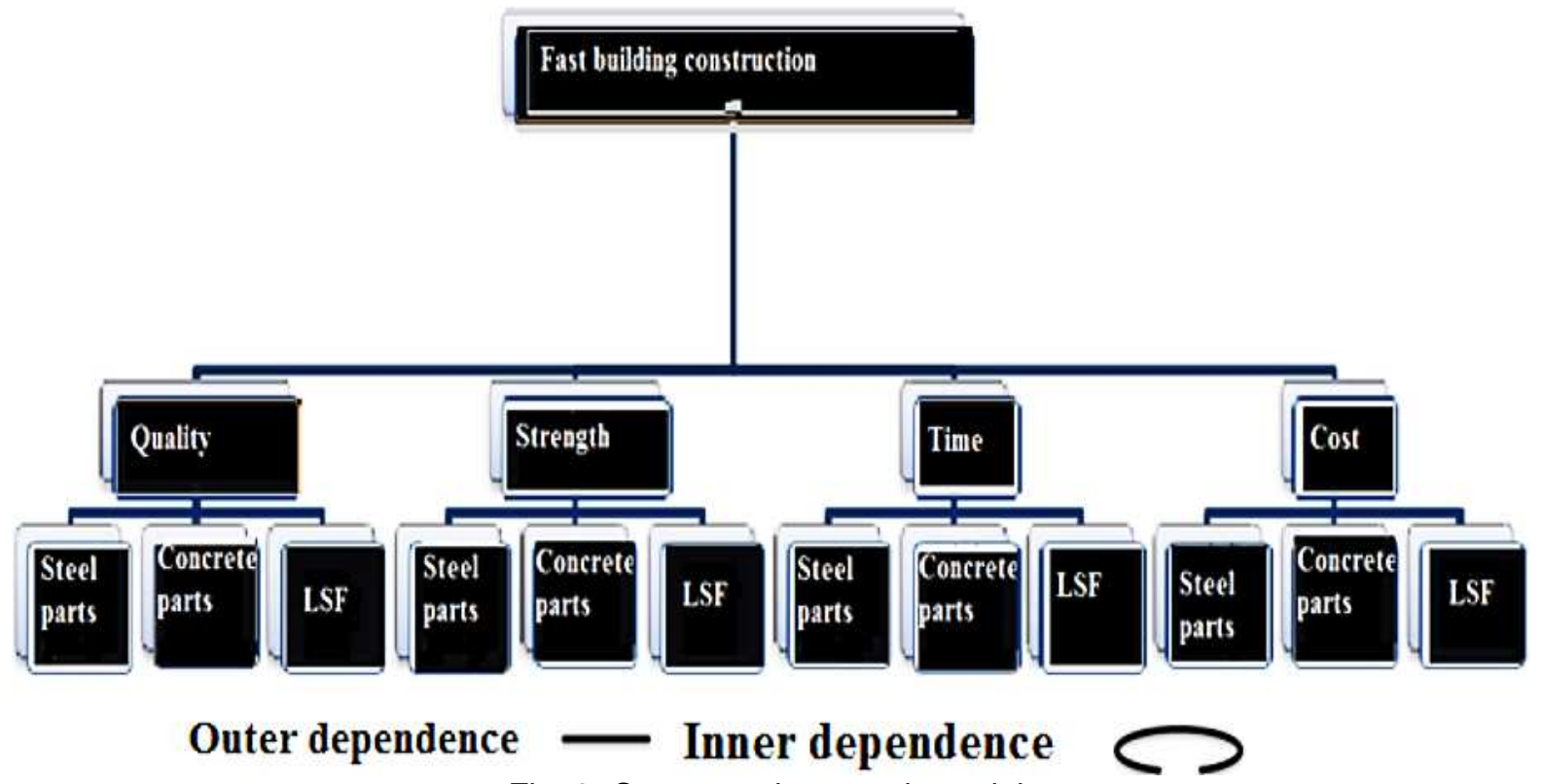

Fig. 3: Conceptual research model.

\section{Results and discussions}

The research method is that with defining the goal, the criteria and options must compare the criteria with each other reciprocally and then the final option is determined based on pairwise comparisons.

The problem should be expressed clearly and analyzed with a logical system. This structure is achieved using decision makers' mind-set through methods such as brainstorming or other appropriate methods. The first step in the analytic network process is to draw a network structure of the problem. In order to form the network structure of the problem, criteria and research options must first be identified. The criteria for this study are quality, time, cost and strength that are presented in Table 1. 
Table 1: List of criteria and research options.

\begin{tabular}{|c|c|c|c|}
\hline \multicolumn{2}{|c|}{ Research criteria } & \multicolumn{2}{c|}{ Research options } \\
\hline No. & Title & No. & Title \\
\hline 1 & cost & 1 & LSF \\
\hline 2 & quality & 2 & steel parts \\
\hline 3 & strength & 3 & concrete parts \\
\hline 4 & time & & \\
\hline
\end{tabular}

With defining the criteria and research options, the relationships between the factors of the network structure of the problem should be identified. In this study, after studying the literature, library studies, and expert opinions, it is concluded that in addition to the linear relationship in the hierarchical structure from bottom to top, there are other relationships.

In the ANP method, several steps should be taken to choose the best option. These steps include making the model, pairwise comparisons, forming a super matrix (including unweighted, weighted and limit super matrices) and choosing the best option. In the first stage that is making the model is the conceptual model of the research, which includes four criteria of quality, time, cost and strength, and three options of LSF, steel and concrete materials. In the second step, which is a pairwise comparison, the criteria and options must be compared with each other reciprocally for determining their priorities. Table 2 shows the results of paired comparison of criteria with respect to the target.

Table 2: The results of paired comparison of criteria with respect to the target.

\begin{tabular}{|l|c|}
\hline \multicolumn{1}{|c|}{ Criteria } & Weight \\
\hline Time & 0.538 \\
\hline Strength & 0.256 \\
\hline Quality & 0.123 \\
\hline Cost & 0.082 \\
\hline Incompatibility rate & 0.0403 \\
\hline
\end{tabular}

Table 3 shows the results of the comparison of options based on the quality criterion.

Table 3: Paired comparisons of options based on quality.

\begin{tabular}{|l|c|}
\hline \multicolumn{1}{|c|}{ Options } & Weight \\
\hline LSF & 0.730 \\
\hline Concrete parts & 0.188 \\
\hline Steel parts & 0.089 \\
\hline Incompatibility & 0.062 \\
\hline
\end{tabular}

Table 4 shows the results of comparing options based on the construction time criterion.

Table 4: Paired comparisons of options based on construction time.

\begin{tabular}{|l|c|}
\hline \multicolumn{1}{|c|}{ Options } & Weight \\
\hline LSF & 0.761 \\
\hline Steel parts & 0.166 \\
\hline Concrete parts & 0.072 \\
\hline Incompatibility rate & 0 \\
\hline
\end{tabular}


Table 5 shows the results of the comparison of options based on the strength criterion.

Table 5: Paired comparisons of options based on strength.

\begin{tabular}{|l|c|}
\hline \multicolumn{1}{|c|}{ Options } & Weight \\
\hline Concrete parts & 0.654 \\
\hline Steel parts & 0.249 \\
\hline LSF & 0.095 \\
\hline Incompatibility rate & 0 \\
\hline
\end{tabular}

Table 6 shows the results of the comparison of options based on the cost criterion.

Table 6: Paired comparisons of options based on cost.

\begin{tabular}{|l|c|}
\hline \multicolumn{1}{|c|}{ Options } & Weight \\
\hline LSF & 0.761 \\
\hline Concrete parts & 0.166 \\
\hline Steel parts & 0.072 \\
\hline Incompatibility rate & 0.070 \\
\hline
\end{tabular}

In the next step, which is the formation of super matrices, the results of the unweighted super matrix are similar to those of the paired comparisons. Table 7 shows the unweighted super matrix of the research model.

Table 7: Unweighted super matrix of research model.

\begin{tabular}{|c|c|c|c|c|c|c|c|c|c|}
\hline & \multicolumn{3}{|c|}{ Options } & \multicolumn{4}{|c|}{ Criteria } & \multirow{2}{*}{ 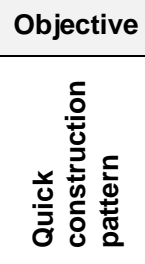 } \\
\hline & & 岃 & 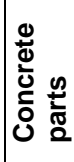 & $\begin{array}{l}\frac{\mathscr{L}}{\Phi} \\
\frac{0}{\Phi} \\
\frac{\Phi}{\omega} \\
\text { के }\end{array}$ & 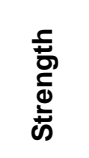 & $\stackrel{\stackrel{\Phi}{\xi}}{\xi}$ & 苑 & 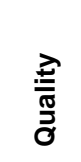 & \\
\hline \multirow{3}{*}{ Options } & LSF & 0 & 0 & 0 & 0.095 & 0.761 & 0.761 & 0.730 & 0.333 \\
\hline & Concrete parts & 0 & 0 & 0 & 0.654 & 0.072 & 0.166 & 0.188 & 0.333 \\
\hline & Steel parts & 0 & 0 & 0 & 0.249 & 0.166 & 0.072 & 0.089 & 0.333 \\
\hline \multirow{4}{*}{ Criteria } & Strength & 0 & 0 & 0 & 0 & 0 & 0 & 0.340 & 0.256 \\
\hline & Time & 0 & 0 & 0 & 0.577 & 0 & 0.750 & 0.595 & 0.538 \\
\hline & Cost & 0 & 0 & 0 & 0.081 & 0.670 & 0 & 0.065 & 0.082 \\
\hline & Quality & 0 & 0 & 0 & 0.342 & 0.330 & 0.250 & 0 & 0.123 \\
\hline Objective & Quick construction pattern & 0 & 0 & 0 & 0 & 0 & 0 & 0 & 0 \\
\hline
\end{tabular}

To form a weighted super-matrix, the (unweighted) matrix is multiplied in the clusters matrix. Therefore, the priorities in the weighted matrix have not changed and only the value of the privileges is smaller. Table 8 shows the weighted matrix of the research model. 
Table 8: Weighted super matrix of research model.

\begin{tabular}{|c|c|c|c|c|c|c|c|c|c|}
\hline & & \multicolumn{3}{|c|}{ Options } & \multicolumn{4}{|c|}{ Criteria } & \multirow{2}{*}{ 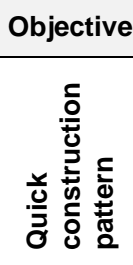 } \\
\hline & & 岕 & 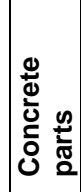 & 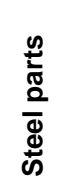 & $\begin{array}{l}\text { 槖 } \\
\text { 离 } \\
\text { 心) }\end{array}$ & $\stackrel{\stackrel{\Phi}{\xi}}{\xi}$ & 苅 & 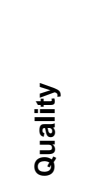 & \\
\hline \multirow{3}{*}{ Options } & LSF & 0 & 0 & 0 & 0.048 & 0.381 & 0.381 & 0.365 & 0.167 \\
\hline & Concrete parts & 0 & 0 & 0 & 0.327 & 0.036 & 0.083 & 0.094 & 0.167 \\
\hline & Steel parts & 0 & 0 & 0 & 0.125 & 0.083 & 0.036 & 0.040 & 0.167 \\
\hline \multirow{4}{*}{ Criteria } & Strength & 0 & 0 & 0 & 0 & 0 & 0 & 0.170 & 0.128 \\
\hline & Time & 0 & 0 & 0 & 0.288 & 0 & 0.375 & 0.298 & 0.269 \\
\hline & Cost & 0 & 0 & 0 & 0.041 & 0.333 & 0 & 0.033 & 0.041 \\
\hline & Quality & 0 & 0 & 0 & 0.171 & 0.167 & 0.125 & 0 & 0.061 \\
\hline Objective & Quick construction pattern & 0 & 0 & 0 & 0 & 0 & 0 & 0 & 0 \\
\hline
\end{tabular}

In addition, to form a limit matrix, all weighted super-matrix elements are raised to the power until divergence is obtained, or all elements of the super matrix are the same. Accordingly, the score of all criteria was equal to the options. Table 9 shows the limit super matrix of the research model.

Table 9: Limit super matrix of model research.

\begin{tabular}{|c|c|c|c|c|c|c|c|c|c|}
\hline & \multicolumn{3}{|c|}{ Options } & \multicolumn{4}{|c|}{ Criteria } & \multirow{2}{*}{ 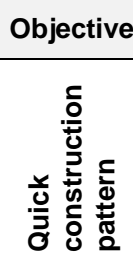 } \\
\hline & & 峁 & 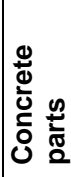 & $\begin{array}{l}\frac{n}{0} \\
\frac{0}{2} \\
\bar{d} \\
\stackrel{\Phi}{\omega}\end{array}$ & 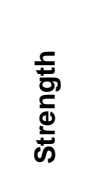 & $\stackrel{\mathscr{\varrho}}{\xi}$ & 离 & 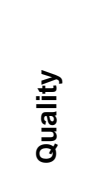 & \\
\hline \multirow{3}{*}{ Options } & LSF & 0 & 0 & 0 & 0.351 & 0.351 & 0.351 & 0.351 & 0.351 \\
\hline & Concrete parts & 0 & 0 & 0 & 0.086 & 0.086 & 0.086 & 0.086 & 0.086 \\
\hline & Steel parts & 0 & 0 & 0 & 0.063 & 0.063 & 0.063 & 0.063 & 0.063 \\
\hline \multirow{4}{*}{ Criteria } & Strength & 0 & 0 & 0 & 0.040 & 0.040 & 0.040 & 0.040 & 0.040 \\
\hline & Time & 0 & 0 & 0 & 0.200 & 0.200 & 0.200 & 0.200 & 0.200 \\
\hline & Cost & 0 & 0 & 0 & 0.144 & 0.144 & 0.144 & 0.144 & 0.144 \\
\hline & Quality & 0 & 0 & 0 & 0.116 & 0.116 & 0.116 & 0.116 & 0.116 \\
\hline Objective & Quick construction pattern & 0 & 0 & 0 & 0 & 0 & 0 & 0 & 0 \\
\hline
\end{tabular}

In the matrix obtained from the criteria according to the objectives, the order of priorities has changed in relation to the previous steps. Table 10 shows the new obtained priorities. Accordingly, the time, cost, strength and quality with the scores of $0.20,0.144,0.116$ and 0.039 have respectively placed in the priorities of first, second, third and fourth.

Table 10: The target limit matrix based on criteria.

\begin{tabular}{|l|c|}
\hline \multicolumn{1}{|c|}{ Criteria } & Weight \\
\hline Time & 0.200 \\
\hline Cost & 0.144 \\
\hline Quality & 0.166 \\
\hline Strength & 0.040 \\
\hline
\end{tabular}


Table 11 contains 3 columns of conclusions. In reality, the column shows the raw results of this research. Accordingly, LSF components with a score of 0.350687 are the first priority, as well as concrete components with a score of 0.086295 and steel parts with a score of 0.063018 are respectively in the second and third priorities. The normal and ideal column also shows the results in the normal and ideal conditions that are calculated through the software.

Table 11: Final rate of options.

\begin{tabular}{|l|c|c|c|}
\hline \multicolumn{1}{|c|}{ Options } & Raw & Normal & Ideal \\
\hline LSF & 0.350687 & 0.701374 & 1 \\
\hline Concrete parts & 0.086295 & 0.172590 & 0.0246074 \\
\hline Steel parts & 0.063018 & 0.126036 & 0.179699 \\
\hline
\end{tabular}

\section{Conclusion}

Based on the results, LSF parts were selected as the best option for construction. This type of structure can be used in the construction of most buildings, such as villas, apartments, restaurants and schools. This construction method is based on the use of galvanized low-thickness steel sheets, which makes the construction speed of these structures higher than other methods. One of the great capabilities of the LSF systems is that they have very little wastes due to the pre-fabricated parts. Precisely before the arrival of these pre-fabricated parts into the workspace, their shape and size have been determined, which this is why they have very little waste. In addition, they occupy very little space in the workshop, and this can help to make a more efficient workspace. The structural systems of LSF have many benefits, including recycling ability, high-speed performance, lightness, design flexibility and safety.

\section{References}

[1] KHODADADEH, Y. - ZIAIE, M.: Investigation on the Existing Tents Disadvantages for the Temporary Resettlement of Earthquake Survivors in Iran and Presenting a Design for the Bouncy Tents. Quarterly Journal of Fine Arts, Vol. 33, № 33, 2007.

[2] KHORRAM, M. - TAYERANI NAJARAN, M. - SADEGHI NAEINI, H.: Temporary Shelter Design Criteria with Earthquake Approach (Case Study: Khorasan Razavi in Iran). Scientific-Research Journal of Iranian Scientific Society of Architecture and Urban Development, 2014.

[3] OLIA, J. - TAGHDIRI, A. - GHANBARZADEH QOMI, S.: Structural Adjustment of Industrial Building Systems. Scientific-research Journal of Iranian Scientific Society of Architecture and Urban Development, № 1, 2010.

[4] HABIBI, K. - SARKARGAR ARDAKANI, A. - YOUSEFI, Z. - SAFDNEJAD, M.: Implementing Fuzzy Hierarchical Algorithms for Determining the Multi-Factor Vulnerability of the Central Core of Cities (Case Study: Tehran 6th District). Scientific-Research Quarterly Journal of Crisis Management, No. 2,2013

[5] ALI MARDANI, A. - MEHRAVARAN, M. - SEDIGHI, H.: Use of Prefabricated Components in Tall Buildings to Lighten. The First Earthquake and Strengthening Conference, Qom University, Faculty of Engineering, 2005.

[6] HABIBI, K. - SARKARGAR ARDAKANI, A. - YOUSEFI, Z. - SAFDNEJAD, M.: Implementing Hierarchical/Fuzzy Algorithms for Determining the Multi-Factor Vulnerability of the Central Core of Cities (Case Study: Tehran 6th district). Research-Scientific Bi-Quarterly Journal of Crisis Management, № 2, 2014.

[7] KALANTARI, M.: Comparison of LSF System with Steel and Concrete Framework Systems. Quarterly Journal of Law Enforcement Engineering Studies, Vol. 5, № 15, 2012.

[8] HEYDARZADEH, SH. - REZAEI ESTEBARAK, Z.: Post-Traumatic Housing Reconstruction Policies in Iran. First National Conference on Geography, Urbanization and Sustainable Development, Tehran, Koomesh Environmental Society, Aviation University, 2013.

[9] KHORRAM, M. - TAYARANI NAJARAN, M. - SADEGHI NAEINI, H.: Temporary Shelter Design Criteria with Earthquake Approach (Case Study: Khorasan Razavi). Scientific-Research Journal of Iranian Scientific Society of Architecture and Urban Development, 2014.

[10] ZARBAST, E.: Application of Analytic Network Process (ANP) in Urban and Regional Planning. Journal of Fine Arts-Architecture and Urban Development, № 41, 2010, pp. 79 - 90. 